\title{
REVIEWS
}

Katarzyna Anna HarŁukowicz ${ }^{\mathrm{A}-\mathrm{D}}$, Urszula KaCZMareK ${ }^{\mathrm{B}-\mathrm{F}}$

\section{Effectiveness of Xylitol in Caries Prevention}

\section{Efektywność ksylitolu w zapobieganiu próchnicy}

Department of Conservative and Pediatric Dentistry, Wroclaw Medical University, Wrocław, Poland

A - research concept and design; B - collection and/or assembly of data; C - data analysis and interpretation;

$\mathbf{D}$ - writing the article; $\mathbf{E}$ - critical revision of the article; $\mathbf{F}$ - final approval of article

\begin{abstract}
Xylitol is a polyol, five-carbon sugar alcohol classified as a natural sugar substitute. Even though its sweetness degree is similar to sucrose, it is less caloric. Dentists became interested in xylitol after the publication of the data of the "Turku sugar studies" in the 1970's, which turned out to be promising in caries reduction. Presently, xylitol is recognized to be a safe dental caries preventive measure, having approval as a dietary food additive. It possesses properties that reduce the levels of Streptococcus mutans bacteria in the dental plaque and saliva due to the disruption of the energy production process leading to bacterial cell death, adhesion reduction to the teeth and less lactic acid production. Xylitol can also cause the disruption of bacterial protein synthesis. Its impact on the remineralization process results from the formation of polyol-Ca complexes, constituting a calcium carrier that leads to a raised level of calcium in dental plaque, where the additional calcium increases remineralization instead of plaque mineralization.

Currently, xylitol is mostly used in chewing gum, chewable or soluble tablets, syrups, mints, mouth-wash liquids and wipes. The AAPD recommends the use of xylitol as a part of a preventive strategy aimed to achieve longterm suppression of cariogenic pathogens and a reduction of caries development in moderate and high caries risk subjects. However, to obtain those goals, a therapeutic dose is needed (Dent. Med. Probl. 2015, 52, 4, 479-484).
\end{abstract}

Key words: xylitol, caries prevention, non cariogenic sweeteners.

Słowa kluczowe: ksylitol, zapobieganie próchnicy, słodziki przeciwpróchnicowe.

Xylitol is a 5-carbon sugar alcohol, alditol, polyol, that has been accepted for use in food, medicines and products for oral health-keeping in a great number of countries. Xylitol has got approval, as a sweetener, from the US FDA in 1963, while the Scientific Committee on Food of the Commission of the European Communities approved it in 1984, classifying the compound with the E967 number. It is also referred to as birch sugar. It is naturally present in some fruits and vegetables, nonetheless, birch, beech, oat, corn or sugarcane bargasse are used as raw materials to extract the compound. It is manufactured, in industrial quantities, by hydrogenation of xylan (hemicellulose), attained from a xylan-rich wooden material through acid hydrolysis. The compound is also formed in the human body in the glucose metabolic process $[1,2]$. Xylitol is considered to be one of the nutritious sweeteners that provide energy. Nonetheless, in comparison with sucrose, it contains fewer calories ( $4 \mathrm{kcal} / \mathrm{g} v s .2 .4 \mathrm{kcal} / \mathrm{g}$, respectively). Due to its mildly sweet taste, it can replace the bulk and sweetness of sugar in foods and enhance the flavor of sugar-free foods.

Ingested xylitol is absorbed by the body only partially, then it is either metabolized (generally by insulin-independent mechanisms) or excreted via the urinary tract, with the unabsorbed compound partially fermented in the colon and excreted. A high level of consumption (45 g per day in children, $100 \mathrm{~g}$ per day in adults) may result in a laxative effect - osmotic diarrhea [3].

When it comes to medical applications, xylitol has been used for a long time in infusion therapy in the patients during post-surgery recovery, as well as in patients suffering from severe burns 
or shock and in the diet of patients suffering from diabetes [4]. Dental practitioners became interested in xylitol after the publication of the results of a cycle of studies named "Turku sugar studies", presenting the multi-dimensional effect a xylitol-based diet has on the oral environment. After 2 years, starting from the moment when sucrose was replaced by xylitol in the food of the adults, it was proven that no caries increment was observed, thus a conclusion was drawn that the non-cariogenic properties of xylitol are related to not being metabolized by salivary and plaque bacteria [5]. Next, in a double-blind study lasting 40 months, the impact on dental caries resulting from the use of chewing gums with xylitol, sorbitol and sucrose by children was compared. The lowest incidence of dental caries was found in the xylitol group [6].

Xylitol is currently used as a preventive measure in the form of chewing gum, chewable or soluble tablets, syrups, mints, mouth-wash liquids, tooth-paste, dental floss and oral wipes that are used to maintain oral hygiene in infants. Jelly beans and other sweets and milk can also be used as a carrier for xylitol $[2,7]$.

\section{Properties and Mechanism of Action}

Xylitol, during dissolution in saliva, similarly to mint, produces a cool feeling in the oral cavity. This feeling results from the fact that xylitol absorbs more heat in the process of dissolution in water than sucrose does.

\section{Impact on Bacteria and Plaque}

Xylitol reduces-plaque formation and bacteria adherence, and it also reduces the degree of Streptococcus mutans adhesion to dental surfaces. Prolonged use of xylitol results in an increase in the number of $S$. mutans strains that are xylitol-resistant. This resistance originates from the fact that these microorganisms have a changed fructose absorption system and are unable to transport xylitol to the bacterial cell in which, after accumulation, it would exhibit a toxic effect. On the other hand, the xylitol-sensitive bacteria transport it to the cell after phosphorylation to xylitol-5-phosphate, via the system relevant for fructose (phosphoenolpyruvate: fructose phosphotransferase). Xylitol-5-phosphate competes with phosphofructokinase, and it may thus hamper the glycolysis process. The xylitol-5-phosphate contained inside the cell is not being metabolized. It reaches toxic levels and needs to be expelled from the cell, after the previous dephosphorylation. The expulsion requires some amount of energy, however it can not be gained from xylitol metabolism. Therefore, xylitol inhibits the growth of the xylitol-sensitive $S$. mutans bacteria by starving the bacteria.

The number of the xylitol-sensitive bacteria decreases with time and xylitol-resistant microorganisms dominate, which are less virulent (i.e. they produce less acids). The study of biofilm containing a xylitol-resistant and xylitol-sensitive $S$. mutans strains have shown that when $5 \%$ xylitol is present, xylitol-resistant $S$. mutans bacteria caused a 10 -fold reduction of unmatured biofilm, however it had no impact on plaque matured for 24 hours. However, the xylitol-resistant strains of $S$. mutans that were not hampered by xylitol did not show the xylitol-induced reduction of the biofilm, thus the decrease of xylitol-resistant strains in the clinically-young biofilm was responsible for the growth inhibition. Moreover, xylitol-resistant bacteria are freed from the plaque into saliva easier, which also decreases the total number of microorganisms present within the dental plaque.

It has also been found that xylitol causes a disruption of bacterial protein synthesis $[2,3,8,9]$. No adaptation of the bacteria to a xylitol metabolism was found, even after one year of using the xylitol chewing gum [10].

\section{Impact on Remineralization}

Xylitol has a number of chemical properties that may be tied to remineralization. A lack of the carbonyl reductive group causes xylitol to be less reactive chemically, thus it is not recognized by the transport mechanisms of cariogenic bacteria. Similarly to other polyols, xylitol has an "additional" number of hydrogen atoms that may be accumulated in other metabolites, including the co-enzymes (e.g. NADP or NAD), forming some reduced metabolism products. Moreover, it can also form complex compounds, with metal cations, including calcium which is important within the scope of the remineralization process.

Xylitol also shows hydrophilic properties due to a number of hydroxyl groups, which makes it easy to be dissolved in saliva. Due to its low molecular weight and hydrophilic nature, it may function as an osmotic regulator. In the oral cavity, xylitol competes against the water molecules, in a struggle to reach the originally hydrous calcium layer, stabilizing the tricalcium phosphate in saliva and in the fluid plaque phase. This stabilization causes the calcium salts and phosphate salts to re- 
main in the solution, even if it is supersaturated. Even though the polyol-Ca complexes are weak, they may constitute a calcium carrier during the remineralization process, which in turn would result in an increase of calcium absorption. Xylitol consumption may result in a raised level of calcium, in dental plaque, where the additional calcium increases remineralization instead of plaque mineralization. Moreover, xylito inhibits D-glucose isomerase [11].

\section{Benefits Resulting from Xylitol Use}

Decreased transmission of cariogenic bacteria. Studies have shown that the introduction of xylitol to primary-primary caries prevention caused a reduction of the cariogenic bacteria reservoir in a mother's oral cavity, resulting from regular chewing of xylitol-containing chewing gum. This results in a reduction or a delay of the child's oral infection by cariogenic bacteria, and thus, the reduction of early childhood caries.

Alamoudi et al. [12, 13], studying mothers of 10-36-month-old children, which were using a chewing gum with $1.8 \mathrm{~g}$ of xylitol three times a day for 3 months, found no significant increase of $S$. mutans number in saliva, as well as no increase in the DMFT value in their children compared to the children of the mothers who were given a fluoride varnish. However, no difference in plaque in the children was found. Therefore, a beneficial impact of xylitol consumption by the mother on caries development and $S$. mutans level in children, in comparison to fluoride varnish application, was found.

The study carried out by Laitala et al. [14] showed that the reduced transmission of $S$. $m u$ tans bacteria from a mother to a child, had a longlasting, beneficial effect on children's dental condition. Retrospective evaluation of the dental condition of children aged 10, whose mothers with a high caries risk used xylitol chewing gum within the period when their children were at the age of 2 to 24 months, revealed that these children remained caries-free for a longer period of time in comparison to the control group (8.2vs. 5.8 years).

However, Thorlid et al. [15] did not find a longterm, beneficial effect regarding the dental condition of 10-year-old children, the mothers of whom used xylitol chewing gum for a year (throughout the period when their children were aged 6 to 18 months), in comparison to the children of mothers using chewing gum with chlorhexidine, xylitol and sorbitol or sodium fluoride, xylitol and sorbitol.

\section{Prevention of Dental \\ Caries Development in Deciduous Teeth}

Studies have shown the rationale for xylitol implementation as a measure of primary caries prevention leading to a reduced level of cariogenic bacteria already existing in the oral cavity even if the caries symptoms are not noticeable. Milgrom et al. [16] studied the effectiveness of administering a syrup containing xylitol or xylitol with sorbitol to children aged $15.0 \pm 2.7$ months old for a period of $10.5 \pm 2.2$ months twice a day. They did not find significant differences in caries incidence that could be linked to the xylitol dose. However, they found that administration twice a day of a total dose of $8 \mathrm{~g}$ of xylitol during the eruption of deciduous teeth could prevent the development of $70 \%$ of carious decay. On the other hand, Zhan et al. [17] found that 6-35-month-old children cleaning their teeth and gums for a year, 3 times a day with the use of special xylitol wipes (daily dose $-4.2 \mathrm{~g}$ of xylitol) additionally to normal toothbrushing twice a day significantly lowers the development of new carious lesions in comparison to the control group (5\% vs. 32\%). Moreover, no changes in the levels of $S$. mutans and Lactobacilli spp. bacteria were noted. Hanno et al. [18], simultaneously administering xylitol to mothers (as a chewing gum) and children (in the form of tablets), 3 times a day for 3 months, reported a significant decrease in the dental plaque index and no difference in caries level in comparison to the control group. Moreover, they also noted that the factors substantially influencing $S$. mutans level were the baseline DMFT values of the children and the S. mutans level of their mothers. Specially designed pacifiers with a special "pocket", where a xylitol tablet is placed, constitute a new form of administration of the medicine to the child's oral cavity. Aaltonen et al. [19] compared the effect of Fludent tablets, containing $0.25 \mathrm{mg}$ of $\mathrm{F}(\mathrm{NaF}), 159 \mathrm{mg}$ of xylitol and $153 \mathrm{~g}$ of sorbitol, applied to 12-monthold children in the pacifier mentioned above or together with the evening meal, in a crushed form. They noted a lower incidence and less frequent occurrence of $S$. mutans bacteria in the dental plaque upper incisors in 2-year-old children receiving the tablet via the pacifier.

Mäkinen et al. [20] evaluated the effectiveness of topical xylitol administration by parents as an element of a caries prevention program. Children whose age ranged from 6 to 36 months were given a $45 \%$ solution of xylitol with the use of cotton swabs once or twice a day on all erupted deciduous teeth. The daily dose of xylitol applied on the den- 
tal surface was approx. $13.5 \mathrm{~g}$. At the age of 7 , in comparison to the control group, a significant reduction of caries was noted in the enamel and dentine, approx. a 2-fold lower caries risk (2.1 and 4.0, respectively) and significantly lower level of $S$. $m u$ tans bacteria. The data indicated that a topical application of xylitol at home constitutes an effective preventive measure complementary to the preventive measures used so far.

The effectiveness of xylitol chewing gum was also evaluated in kindergarten children. Its effectiveness was shown in decreasing the $S$. mutans level within the dental plaque of 3-4-year-old children following its use for 3 months [21]. However, according to AADP guidelines, chewing gum should not be recommended for children less than 4 years of age, due to the risk of choking [2].

The cariostatic effectiveness of xylitol delivered to the oral environment by toothpaste was also studied in small children. However, no significant differences in the caries incidence and the level of $S$. mutans between the children brushing their teeth with a toothpaste with $1400 \mathrm{ppm}$ of fluoride and $31 \%$ of xylitol and the children using a toothpaste with $1450 \mathrm{ppm}$ of fluoride and sorbitol were found [22].

\section{Prevention of Caries Development in Permanent Teeth in Children}

Hujoel et al. [23] presented a long-term reduction of caries-risk as the result of xylitol chewing gum use. After administration to 6-year-old children for 2 years of chewing gum with xylitol, sorbitol or a mixture of xylitol and sorbitol, they found after 5 years a $59 \%$ reduction in caries risk in the xylitol group and $44 \%$ in the xylitol-sorbitol group. This long-term caries risk reduction was related to the process of tooth eruption, as when teeth appeared after 1 or 2 years from the time of chewing gums use, the reduction was $93 \%$ and $88 \%$, respectively. Therefore, in order to maximize the longterm preventive effect, one should introduce xylitol chewing gum at least one year before eruption of the permanent teeth. By contrast, use for 1-2 years by older children, 10 years old, of lozenges containing xylitol (4.7 g) and maltitol (4.6 g) or erythritol (4.2 g) and maltitol (4.2 g) did not cause a caries reduction after 4 years from the baseline (i.e. from the moment when the use of the polyols began) [24].

In order to prevent dental caries in schoolchildren, toothpastes with xylitol were also used, however here the results were inconsistent. Sintes et al. [25] presented a significant reduction of den- tal surfaces filled and caries-affected (at 12.3\%) after the use of a toothpaste with $0.243 \% \mathrm{NaF}$ and $10 \%$ xylitol content in a silica basis for 3 years by 8-10-year-old children.

Contrarily, Cutress et al. [26] did not note any impact of xylitol of a quantity $15 \mathrm{mg} / \mathrm{g}$ (15\%) added to toothpastes with a varied fluoride content (1250, 2500 and $5000 \mathrm{ppm})$ on caries incidence in permanent teeth. Nonetheless, they did observe a negative relationship between DMFT values and fluoride concentration. In turn, Subrananiam et al. [27] evaluated the level of S. mutans in the dental plaque of 7-13-year-old children rinsing the oral cavity, under supervision, with a mouthrinse containing 5\% xylitol, $0.05 \% \mathrm{NaF}$ and $0.03 \%$ triclosan or $0.12 \%$ chlorhexidine twice a day for 3 weeks. They did not find any significant difference in the reduction of $S$. mutans level between the mouthrinses.

Alternatively, xylitol can be introduced into the oral environment of kindergarten and school children in the form of a gummy-bear snack [28-30]. Ly et al. [29] evaluated the efficiency of the administration 3 times a day of such snacks containing doses of xylitol, in total reaching up to $15.9 \mathrm{~g}$ and $11.7 \mathrm{~g}$, and $44.7 \mathrm{~g}$ maltitol, on the levels of $S$. $m u$ tans, S. sobrinus and Lactobacilli spp. in dental plaque. After 6 weeks, a reduction of $S$. mutans and $S$. sobrinus was noted, however no differences occurred in the level of Lactobacilli spp. bacteria. Instead, Lee et al. [30], administering xylitol (7.8 g/day) to 5-6-year-old children 3 times a day within 9 months, or alternatively a placebo (inulin, $20 \mathrm{~g} /$ day) in the form of gummy bears, found a lower caries incidence in children that were receiving xylitol.

\section{Prevention of Dental Caries in Adults}

A study based on a numerous group of adults aged 21-80, who received chewable tablets containing $1 \mathrm{~g}$ of xylitol over a period of 33 months, 5 times a day, showed a $40 \%$ reduction of root caries and a $10 \%$ reduction (statistically insignificant) of coronal caries compared to the placebo control group [31-33]. This data leads to the conclusion that the caries preventive effect of xylitol is mainly caused by its impact on dental plaque and cariogenic bacteria. However, continuous and long-term exposure of teeth to xylitol is required, regardless of the carrier used. The most common form of xylitol administration is use of a chewing gum. Not only does this carrier release xylitol gradually, and thus the teeth are in contact with the substance for a longer period of time, but it also provides me- 
chanical and taste stimulation, which in turn increases the salivary secretion, which increases its buffering capacity, and this can help in caries reduction. The dentist should recommend a suitable form of xylitol for a given patient and the clinical situation, e.g. chewing gum is not recommended for children aged under 4 and for patients suffering from temporomandibular joint disorders.

The American Academy of Pediatric Dentistry (AAPD) endorses the use of xylitol as a part of a preventive strategy, the aim of which is to achieve long-term suppression of cariogenic pathogens, and in order to reduce caries development in patients with moderate and high caries risk [2, 4]. The Academy also stresses the fact that, according to the current state of the art, the total daily dose should be in the range of 3 to $8 \mathrm{~g}$, in order to obtain the cariostatic effect, with the use of the currently applied forms of supply (syrup, chewing gum, mints, lozenges, gummy bears). The dose should be administered at least twice a day and not exceed 8 g per day [2]. Table 1 presents the AAPD recommendations.

Xylitol is safe for children if it is consumed in therapeutic quantities suitable for caries prevention. Thus, parents should control xylitol intake. By recommending the use of xylitol, the dentist should inform the patient about the undesirable
Table 1. AAPD recommendations regarding the xylitol use for children at moderate or high caries risk (2)

\begin{tabular}{|l|l|l|}
\hline Age & Product & Dose \\
\hline$\leq 4$ years & Syrup & $\begin{array}{l}3-8 \mathrm{~g} / \text { day, } \\
\text { divided dose }\end{array}$ \\
\hline$\geq 4$ years & $\begin{array}{l}\text { age-appropriate pro- } \\
\text { ducts: chewing gum } \\
\text { mints, lozenges, gum- } \\
\text { my bears snack food }\end{array}$ & $\begin{array}{l}3-8 \text { g/day, } \\
\text { divided dose }\end{array}$ \\
\hline
\end{tabular}

${ }^{*} \mathrm{AAPD}$ does not recommend the use of chewing gum in children less than 4 years old due to choking risk.

side-effects, such as osmotic diarrhea and gas production, occurring when larger quantities of $x y-$ litol are consumed. These symptoms disappear once intake of xylitol is ceased or reduced. In order to minimize the symptoms mentioned above, $\mathrm{xy}-$ litol should be introduced gradually, during a period of one week or longer, so that the body is able to get used to this specific polyol [2].

In conclusion, one may state that in light of the current state of the art, xylitol use is a proven and effective complementary measure of caries prevention at any level (primary-primary, primary and traditional) among subjects with moderate and high caries risk, especially in pediatric patients.

\section{References}

[1] Mortensen A.: Sweeteners permitted in the European Union: safety aspects. Scand. J. Food Nutr. 2006, 50, $104-116$.

[2] Guideline on xylitol use in caries prevention. AAPD guideline, Reference manual 2014/15, 36, 175-178.

[3] Nayak P.A., Nayak U.A., Khandelwal V.: The effect of xylitol on dental caries and oral flora. Clin. Cosm. Investig. Dent. 2014, 6, 89-94.

[4] Policy on the use of xylitol in caries prevention. AAPD Guidelines Reference manual 2014/15, 36, 45-47.

[5] Scheinin A., Mäkinen K.K., Ylitalo K.: Turku sugar studies. V. Final report on the effect of sucrose, fructose and xylitol diets on the caries incidence in man. Acta Odontol. Scand. 1976, 34, 179-216.

[6] Mäkinen K.K., Bennett C.A., Hujoel P.P., Isokangas P.J., Isotupa K.P., PAPe H.R. JR, Mäkinen P.L.: Xylitol chewing gums and caries rates: a 40-month cohort study. J. Dent. Res. 1995, 74, 1904-1913.

[7] Castillo J.L., Milgrom P., Coldwell S.E., Castillo R., Lazo R.: Children's acceptance of milk with xylitol or sorbitol for dental caries prevention. BMC Oral Health, 2005, 5, 6, doi: 10.1186/1472-6831-5-6.

[8] Decker E-M., Klein C., Schwindt D., von Ohle C.: Metabolic activity of Streptococcus mutans biofilms and gene expression during exposure to xylitol and sucrose. Int. J. Oral Sci. 2014, 6, 195-204.

[9] Marttinen A.M., Ruas-Madiedo P., Hidalgo-Cantabrana C., Saari M.A., Ihalin R.A., Söderling E.M.: Effects of xylitol on xylitol-sensitive versus xylitol-resistant Streptococcus mutans strains in a three-species in vitro biofilm. Curr. Microbiol. 2012, 65, 237-243.

[10] Larmas M., Scheinin A., Gehring F., Mäkinen K.K.: Turku sugar studies XX. Microbiological findings and plaque index values in relation to 1-year use of xylitol chewing gum. Acta Odontol. Scand. 1976, 34, 381-396.

[11] MÄKInen K.K.: Sugar alcohols, caries incidence, and remineralization of caries lesions: a literature review. Int. J. Dent. 2010, 981072. doi: 10.1155/2010/981072.

[12] Alamoudi N.M., Hanno A.G., Sabbagh H.J., Masoud M.I., Almushayt A.S., El Derwi D.A.: Impact of maternal xylitol consumption on mutans streptococci, plaque and caries levels in children. J. Clin. Pediatr. Dent. 2012, 37,163-166.

[13] Alamoudi N.M., Hanno A.G., Almushayt A.S., Masoud M.I., El Ashiry E.A., El Derwi D.A.: Early prevention of childhood caries with maternal xylitol consumption. Saudi. Med. J. 2014, 35, 592-597.

[14] Laitala M.L., Alanen P., Isokangas P., Söderling E., PienihäKkinen K.: Long-term effects of maternal prevention on children's dental decay and need for restorative treatment. Community Dent. Oral Epidemiol. 2013, 41, 534-540.

[15] Thorild I., Lindau B., Twetman S.: Long-term effect of maternal xylitol exposure on their children's caries prevalence. Eur. Arch. Paediatr. Dent. 2012, 13, 305-307. 
[16] Milgrom P., Ly K.A., Tut O.K., Mancl L., Roberts M.C., Briand K., Gancio M.J.: Xylitol pediatric topical oral syrup to prevent dental caries: a double-blind randomized clinical trial of efficacy. Arch. Pediatr. Adolesc. Med. 2009, 163, 601-607.

[17] Zhan L., Cheng J., Chang P., Ngo M., Denbesten P.K., Hoover C.I., Featherstone J.D.: Effects of xylitol wipes on cariogenic bacteria and caries in young children. J. Dent. Res. 2012, 91(7 Suppl), 85S-90S.

[18] Hanno A.G., Alamoudi N.M., Almushayt A.S., Masoud M.I., Sabbagh H.J., Farsi N.M.: Effect of xylitol on dental caries and salivary Streptococcus mutans levels among a group of mother-child pairs. J. Clin. Pediatr. Dent. 2011, 36, 25-30.

[19] Aaltonen A.S., Suhonen J.T., Tenovuo J., Inkilä-SaAri I.: Efficacy of a slow-release device containing fluoride, xylitol and sorbitol in preventing infant caries. Acta Odontol. Scand. 2000, 58, 285-292.

[20] MäKinen K.K., Järvinen K.L., Anttila C.H., Luntamo L.M., VAhlberg T.: Topical xylitol administration by parents for the promotion of oral health in infants: a caries prevention experiment at a Finnish Public Health Centre. Int. Dent. J. 2013, 63, 210-224.

[21] Seki M., Karakama F., Kawato T., Tanaka H., Saeki Y., Yamashita Y.: Effect of xylitol gum on the level of oral mutans streptococci of preschoolers: block-randomised trial. Int. Dent. J. 2011, 61, 274-280.

[22] Chi D.L., Tut O., Milgrom P.: Cluster-randomized xylitol toothpaste trial for early childhood caries prevention. J. Dent. Child. (Chic). 2014, 81, 27-32.

[23] Hujoel P.P., Mäkinen K.K., Bennett C.A., Isotupa K.P., Isokangas P.J., Allen P., Mäkinen P.L.: The optimum time to initiate habitual xylitol gum-chewing for obtaining long-term caries prevention. J. Dent. Res. 1999, 78, 797-803.

[24] Lenkkeri A.M., Pienihäkninen K., Hurme S., Alanen P.: The caries-preventive effect of xylitol/maltitol and erythritol/maltitol lozenges: results of a double-blinded, cluster-randomized clinical trial in an area of natural fluoridation. Int. J. Paediatr. Dent. 2012, 22, 180-190.

[25] Sintes J.L., Escalante C., Stewart B., McCool J.J., Garcia L., Volpe AR., Triol C.: Enhanced anticaries efficacy of a $0.243 \%$ sodium fluoride/10\% xylitol/silica dentifrice: 3-year clinical results. Am. J. Dent. 1995, 8, $231-235$.

[26] Cutress T., Howell P.T., Finidori C., Abdullah F.: Caries preventive effect of high fluoride and xylitol containing dentifrices. ASDC J. Dent. Child. 1992, 59, 313-318.

[27] Subrananiam P., Nandan N.: Effect of xylitol, sodium fluoride and triclosan containing mouth rinse on Streptococcus mutans. Contemp. Clin. Dent. 2011, 2, 287-290.

[28] Milgrom P., Tut O.K.: Evaluation of Pacific Islands Early Childhood Caries Prevention Project: Republic of the Marshall Islands. J. Public Health Dent. 2009, 201-203.

[29] Ly K.A., Riedy C.A., Milgrom P., Rothen M., Roberts M.C., Zhou L.: Xylitol gummy bear snacks: a schoolbased randomized clinical trial. BMC Oral Health, 2008, 25, 8, doi: 10.1186/1472-6831-8-20.

[30] Lee W., Spiekerman C., Heima M., Eggertsson H., Ferretti G., Milgrom P., Nelson S.: The effectiveness of xylitol in a school-based cluster-randomized clinical trial. Caries Res. 2015, 49, 41-49.

[31] Ritter A.V., Bader J.D., Leo M.C., Preisser J.S., Shugars D.A., Vollmer W.M., Amaechi B.T., Holland J.C.: Tooth-surface-specific effects of xylitol: randomized trial results. J. Dent. Res. 2013, 92, 512-517.

[32] Bader J.D., Vollmer W.M., Shugars D.A., Gilbert G.H., Amaechi B.T., Brown J.P., Laws R.L., Funkhouser K.A., Makhija S.K., Ritter A.V., Leo M.C.: Results from the xylitol for adult caries trial (X-ACT). J. Am. Dent. Assoc: 2013, 144, 21-30.

[33] Brown J.P., Amaechi B.T., Bader J.D., Gilbert G.H., Makhija S.K., Lozano-Pineda J., Leo M.C., Chen C., Vollmer W.M.: X-ACT Trial Collaborative Group. Collaborators Visual scoring of non cavitated caries lesions and clinical trial efficiency, testing xylitol in caries-active adults. Community Dent. Oral Epidemiol. 2014, $42,271-278$.

\section{Address for correspondence:}

Katarzyna Anna Harłukowicz

Department of Conservative and Pediatric Dentistry

Wroclaw Medical University

Krakowska 26

50-425 Wrocław

Poland

E-mail: ktarnawa@o2.pl

Conflict of interest: None declared

Received: 02.07.2015

Revised: 19.07.2015

Accepted: 28.07.2015 